\title{
A IDEALIZAÇÃO DO AMBIENTE DE TRABALHO DO GOOGLE
}

\author{
THE IDEALIZATION OF GOOGLE'S WORKING ENVIRONMENT
}

\section{LA IDEALIZACIÓN DE MEDIO AMBIENTE DE TRABAJO DEL GOOGLE}

Tânia Oliveira Pereira

Mestranda, Universidade de São

Paulo

tania.pereira@usp.br

Maria Aparecida Ferrari

Doutora, Universidade Federal de São Paulo

maferrar@usp.br

\section{Resumo}

A proposta deste artigo é refletir sobre o ambiente de trabalho do Google, empresa norteamericana de tecnologia, mundialmente reconhecida pelo seu serviço de busca, que processa mais de um bilhão de solicitações de pesquisa por dia. Para tanto, a partir do nosso referencial teórico, analisaremos esse ambiente a partir das percepções de cinco trabalhadores do escritório da empresa em São Paulo, capturadas em uma sondagem realizada pela autora. A intenção é compreender como é o real ambiente de trabalho do Google, muito idealizado por milhares de trabalhadores, sobretudo os ingressantes no mercado, os jovens da chamada Geração Y.

Palavras-chave: Comunicação. Mundo do Trabalho. Ambiente de Trabalho. Google.

\begin{abstract}
The purpose of this article is to reflect about the working environment of Google, an american company of technology, recognized worldwide for its search service, which processes over one billion search requests a day. Therefore, from our theoretical framework, we will examine this environment from the perceptions of five workers from the company's office in São Paulo, captured in a survey conducted by the author. The intention is to understand how the real working environment of Google, much idealized by thousands of workers, especially those entering the market, the youth of the so-called Generation Y.
\end{abstract}

Key words: Communication. World of Work. Working Environment. Google. 


\section{Resumen}

El propósito de este artículo es reflexionar sobre el entorno de trabajo de Google, una empresa estadounidense de tecnología, reconocida mundialmente por su servicio de búsqueda, que procesa más de mil millones de peticiones de búsqueda al día. Por lo tanto, desde nuestro marco teórico, vamos a examinar este ambiente de las percepciones de los cinco trabajadores de la oficina de la empresa en São Paulo, capturado en la encuesta realizada por el autor. La intención es comprender cómo el entorno de trabajo real de Google, tanto idealizada por miles de trabajadores, especialmente los que entran en el mercado, los jóvenes de la llamada Generación Y.

Palabras clave: Comunicación. Mundo del Trabajo. Medio Ambiente de Trabajo. Google.

\section{INTRODUÇÃO}

Que a sociedade está em constante transformação, disso não há dúvida. A Amazon, por exemplo, é uma livraria sem portas nem fronteiras, que vende 180 livros em formato Kindle para cada um vendido em papel; o Facebook, com o seu número de usuários, seria o terceiro maior país do mundo e o YouTube recebe 35 horas de vídeo a cada minuto (RADFAHRER, 2012, p. 28). E esse incessante avanço tecnológico, intensificado no século passado, está possibilitando novas formas de interação com a realidade, gerando gradativamente mudanças no comportamento das pessoas, inclusive no mundo do trabalho. Há poucos anos, quem poderia imaginar que as mídias sociais invadiriam o nosso cotidiano? Que um buscador virtual como o Google processaria um bilhão de pesquisas por dia? Que blogueiros individuais repercutiriam sem qualquer amparo da grande imprensa? Que manifestações de milhares de pessoas seriam convocadas via Facebook e polêmicas colossais nasceriam a partir do Twitter?

Neste cenário de transição, queremos analisar o caso do Google como empregador idealizado por milhares de jovens que entram no mercado de trabalho, sobretudo os da chamada Geração $\mathrm{Y}^{1}$. O que significa uma empresa de tecnologia, sem uma linha de produção tradicional, ser considerada a melhor empresa para se trabalhar por três anos consecutivos, de acordo com a pesquisa do Great Place to Work, publicada pela revista Época (SILVEIRA, 2012)? Não temos uma resposta precisa, mas acreditamos que isso indica o início de uma grande revolução no mundo do trabalho; por isso, neste artigo, queremos refletir sobre a idealização do ambiente de trabalho do Google.

\footnotetext{
${ }^{1}$ Também conhecida como geração da internet ou geração do milênio, é formada por jovens nascidos entre os anos 1980 até meados dos anos 1990.
} 


\section{DESENVOLVIMENTO}

\subsection{Um breve panorama do mundo do trabalho}

Ao recuperar os embates da filosofia em uma apresentação bastante didática de "A Ideologia Alemã", Emir Sader (MARX; ENGELS, 2007, p. 14) afirma que "o homem se diferencia dos outros animais por muitas características, mas a primeira, determinante, é a capacidade de trabalho. Enquanto os outros animais apenas recolhem o que encontram na natureza, o homem, ao produzir as condições da sua sobrevivência, a transforma”. Então, acreditamos que no cerne do ser humano está o trabalho. E que, a partir dele, construímos nossas relações e a própria sociedade em que vivemos. Como conceituação do termo trabalho, trabalharemos com a proposta por Figaro (2009, p. 35), de que "o trabalho é atividade humana que comporta uma herança cultural e história das técnicas, da experiência das gerações passadas e da experiência pessoal, o que permite ao homem uma transcendência criativa".

Dessa maneira, acreditamos que o trabalho pode ser compreendido como a força humana para transformar a natureza, criando valor na sociedade. No capitalismo, o esforço é o tempo todo de dominar a capacidade de consciência e propósito do homem no trabalho. Assim, a divisão do trabalho faz parte da própria lógica do capitalismo (apesar de ser anterior a ele), e foi muito importante para organizar a sociedade. A primeira divisão existente foi estabelecida entre o homem e a mulher: enquanto o homem saía para caçar, fazer guerras e expandir territórios, a mulher tinha menos mobilidade, ficando responsável pela agricultura, o cuidado com os filhos e os afazeres domésticos. Mas esse fenômeno da divisão do trabalho começou a ser estudado com mais profundidade a partir das teorias de Frederick Taylor e sua Administração Científica, que buscou padronizar os tempos e movimentos da linha de produção. O engenheiro norte-americano foi o pioneiro na proposição de métodos científicos na administração de empresas. Seu foco era elevar a produtividade industrial, e seu processo cartesiano o levou a pensar o corpo como uma ferramenta. Sua metodologia foi baseada em estudos detalhados e bastante racionais, gerando metaforicamente a figura do "homem-boi" (FIGARO, 2010), que o clássico filme Tempos Modernos, de Charles Chaplin, retrata com excelência. No entanto, se engana quem acredita que o método taylorista está totalmente ultrapassado. Para nós, o controle hoje é mais sutil e muito mais invasivo, pois cada vez mais o trabalhador perde a sua identidade e é forçado a assumir a identidade corporativa.

Ainda assim, o trabalhador sempre está inovando, mesmo que sem o devido reconhecimento. É preciso tempo e às vezes até um pouco de sorte para o que é considerado 
uma "gambiarra" no ambiente fabril (muitas vezes uma forma de rebelião contra a máquina) seja considerado uma inovação pela gestão. Porque não pode ser qualquer inovação: o mundo do trabalho quer o novo que gere capital. Aqui se destaca a importância do inédito do trabalho, pois, mesmo com o rápido desenvolvimento da tecnologia desde o século passado, o trabalho humano é insubstituível. É bem verdade que ele pode ser potencializado com o suporte da tecnologia, mas jamais será substituído, porque os robôs e computadores não trabalham, eles fazem somente o que está prescrito: é preciso o trabalho humano para ativar o trabalho morto armazenado nas máquinas.

Esse inédito, característica inerente do trabalho humano, é o que o diferencia do "trabalho" animal, que é instintivo e sem criatividade. Muitas vezes, o trabalhador tem dificuldade de conceituar o seu trabalho com palavras, ou seja, não tem consciência verbal de como faz o seu trabalho, mas isso não o caracteriza como um movimento instintivo. Inclusive, essa é uma diferença importante que queremos destacar entre homens e animais: o animal não trabalha, ele apenas segue o seu instinto. Mesmo o bicho-da-seda ou a abelha, que são considerados símbolos do trabalho animal, estão apenas seguindo o seu instinto para produzir a seda ou o mel, e sempre o farão da mesma forma. Em nossa concepção, o máximo de evolução que pode ocorrer neste sentido é o adestramento animal, em que o animal desenvolve novas habilidades de forma condicionada, sem realizar escolhas ou imprimir uma maneira própria de desenvolver determinada atividade.

As diferentes classes se relacionam com o trabalho de maneira diferente: ao mesmo tempo em que pessoas são estimuladas a participar, outras são tidas puramente como executoras. No entanto, a verdade é que são estimuladas apenas as ideias direcionadas para o interesse do capital. Voltamos a pontuar que se pode entender a inovação, tão em voga na sociedade contemporânea, como o que agrega valor ao capital: se a ideia não agregar valor de mercado ao capital, não é considerada inovação. Na verdade, acreditamos que esse controle das ideias explora ainda mais o trabalho, reforçando claramente a sua divisão: uns são pagos para pensar, enquanto outros são pagos para executar. Podemos ilustrar com um exemplo bastante atual: enquanto um estilista italiano desenha peças para sua grife, caríssimas, de prestígio internacional, são os costureiros vietnamitas que materializam sua produção, em condições de trabalho precárias e a um salário de fome.

Os conceitos de trabalho e consumo, inclusive, estão muito interligados, pois é o trabalho que irá produzir as mercadorias que se deseja consumir, satisfazendo as necessidades humanas de qualquer espécie. O trabalho, ele mesmo, é uma forma de mercadoria, que cria valor e se renova. No sistema capitalista, há uma clara necessidade da existência de uma 
massa assalariada que possa consumir o que é produzido. O ciclo inerente do capital está baseado na produção e no consumo, por isso ele é cada vez mais estimulado. Mesmo os antes considerados "bens duráveis" padecem frente a essa lógica: se o indivíduo fica muito tempo com a mercadoria, ele destrói o seu valor de troca como, por exemplo, no caso de um automóvel ou de um telefone celular.

Independente da forma de produção é importante deixar claro que ninguém vende a sua força de trabalho, pois isso é característica do humano. Conforme Braverman (1981, p. 56), "o trabalho, como todos os processos vitais e funções do corpo, é uma propriedade inalienável do indivíduo humano. [...] Deste modo, na troca, o trabalhador não entrega ao capitalista a sua capacidade para o trabalho". Ou seja, o homem não vende a sua força de trabalho, mas sim um período do seu tempo em que ele se dedica ao trabalho. Esse pagamento, no entanto, é sempre parcial, pois o trabalho gera um valor maior que o pagamento recebido. Há, então, claramente, uma diferença entre trabalho como o que se entrega ao capitalista e como função inalienável do ser humano.

Apesar das determinações formais de um contrato de trabalho, o trabalho real sempre se dá no inédito da ação. Ao mesmo tempo em que espera que alguém lhe diga o que fazer, o trabalhador "sabe" o que tem que fazer. Podemos citar como exemplo o processo produtivo de uma linha de produção: mesmo sendo um trabalho mecânico, com prescrições bem definidas, há o operário e o trabalho dele, e um modo pessoal e quase secreto de executar suas tarefas. $\mathrm{O}$ trabalho do homem é sempre conhecimento, mesmo que aparentemente seja algo bastante simples, como varrer o chão.

\subsection{A centralidade do trabalho e a hegemonia dos discursos}

A linguagem produz sentido nas interações sociais e, também por isso, é fundamental, entre outros aspectos, para compreender a complexidade da comunicação no mundo do trabalho. Porque não se trabalha sem comunicação, nunca se trabalhou. Ela é a forma de processo e controle do trabalho, apesar de não existir comunicação sem ruído (e nem devemos tentar impedi-lo, pois isso apenas demonstraria nossa ignorância sobre o processo comunicacional). De acordo com Figaro (2012, p. 10), "trata-se de entendê-lo [o conceito de comunicação] como característica constitutiva do humano, presente em toda relação social, inclusive nas formas de organização institucional e econômica, incorporado aos processos produtivos". Nesta linha, Nouroudine (2002, p. 21) afirma que a "complexidade do trabalho e complexidade da linguagem, de um certo ponto de vista, se confundem". 
Para compreender a relação entre pensamento e linguagem, Vigotski (2005) examina o significado da palavra, que ele considera sua unidade de estudo, destacando a importância fundamental do contexto. Para ele, o significado se constitui, justamente, em um determinado contexto de fala e de cultura. Vale apenas ressaltar o que afirma Schaff (1976, p. 251), quando diz que "a linguagem não é o único fator que determina o nosso pensamento; é, contudo, um fator de uma enorme potência de ação e de uma grande importância". A criança, então, aprende a falar, do ponto de vista do enunciado, do concreto para o abstrato, do particular para o geral. Antes mesmo de ter um contato formal com as palavras e a linguagem, ela aprende por meio da observação e de estímulos ambientais a perceber o mundo que a envolve. Durante o seu desenvolvimento, o pensamento e a fala têm origens diferentes, mas em certa altura essas linhas se encontram, e o pensamento torna-se verbal. Mais ou menos aos dois anos de idade,

a criança sente a necessidade das palavras e, ao fazer perguntas, tenta ativamente aprender os signos vinculados aos objetos. Ela parece ter descoberto a função simbólica das palavras. A fala, que na primeira fase era afetiva-conativa, agora passa para a fase intelectual. (VIGOTSKI, 2005, p. 53-53).

A potencialidade do cruzamento linguagem e pensamento está presente em todos os seres humanos, pois, em princípio, todas as pessoas podem aprender a falar, salvo aquelas que têm algum problema de ordem psíquica ou biológica. O que Vigotski defende, então, é que esse desenvolvimento vai depender dos estímulos sociais recebidos. Para ele, "a função primordial da fala é a comunicação, o intercâmbio social.” (VIGOTSKI, 2005, p. 6). Adam Schaff tem uma visão mais centrada na cultura para analisar os conceitos de linguagem. Segundo ele (1976, p. 268), “a linguagem, [é] não só um dos elementos, mas também um dos co-criadores da cultura". O estudioso acredita que ela influencia a forma de conhecer e entender o mundo, pois a realidade se apresenta de forma diferenciada para cada cultura. A tradução, por exemplo, não é uma cópia, pelo contrário, é sempre uma recriação, dependendo da cultura em que é produzida. Para ele,

a linguagem, que é um reflexo específico da realidade, é também, em certo sentido, a criadora da nossa imagem do mundo. No sentido em que a nossa articulação do mundo é pelo menos, em certa medida, a função da experiência, não só individual, mas também social, transmitida ao indivíduo 
pela educação e, antes de tudo, pela linguagem. (SCHAFF, 1976, p. 254255)

Ele acredita que o olho do ser humano enxerga as coisas de sua cultura como, por exemplo, os esquimós, que diferenciam vários tons de branco na neve. Dessa maneira, podemos afirmar que a linguagem compreende a realidade do homem, o conhecimento desta realidade e de sua constante modificação através da elaboração desta como criação humana. A linguagem é influenciada por mudanças na vida social, contatos com culturas estrangeiras e progressos da civilização. No mundo do trabalho, por exemplo, cada profissão tem um jargão, uma linguagem própria. Nosso universo cotidiano, nossos hábitos e costumes, nossa cultura e nossas crenças são moldadas - de forma inconsciente - pela linguagem. Por isso, concordamos com Schaff que a língua é um organismo vivo:

apesar do seu conservantismo, as línguas não são imutáveis. Pelo contrário, sofrem modificações constantes, sobretudo na sua matéria semântica. Esse fato é atribuível a diversas causas: as mudanças na vida social acarretam consigo a necessidade de modificar a linguagem, quando mais não fosse enriquecendo o seu léxico; em efeito análogo é causado pelos contatos com as culturas estrangeiras, que agem sobre a linguagem por contágio. (SCHAFF, 1976, p. 261).

Fica muito claro então que a língua e a comunicação não são instrumentos ou ferramentas, pois a linguagem é constitutiva do ser humano, que precisa dela para desenvolver o pensamento conceitual. A função primordial da linguagem é a comunicação, que não está necessariamente ligada aos sons. Para Vigotski (2005, p. 47), "não importa qual o meio, mas sim o uso funcional dos signos, de quaisquer signos que pudessem exercer um papel correspondente ao da fala nos homens". O pensamento conceitual foi criado porque existia um meio particular que propiciou o desenvolvimento da espécie humana. Pouco a pouco, o homem foi criando artefatos e se transformando para poder usar esses artefatos. Os signos são o elemento crucial da transformação desse animal em homem, pois com ele são criadas a subjetividade e, por consequência, o conceito de representação e abstração. Então, a esfera ideológica é a esfera do signo. Tudo o que é ideológico é um signo. Ele compõe a realidade, pois é parte do mundo exterior e se dá através das relações sociais. Uma caneta Mont Blanc, por exemplo, é um corpo físico, mas também é um signo, pois mais do que uma caneta, é também um símbolo de prestígio e status social. Para Bakhtin, 
um produto ideológico faz parte de uma realidade (natural ou social) como todo corpo físico, instrumento de produção ou produto de consumo; mas, ao contrário destes, ele também reflete e refrata uma outra realidade, que lhe é exterior. Tudo que é ideológico possui um significado e remete a algo situado fora de si mesmo. Em outros termos, tudo que é ideológico é um signo. (BAKHTIN, 2002, p. 31).

Aqui queremos destacar a particularidade do humano e o inédito do discurso: "eu" recebo diversos discursos, mas "eu" produzo um novo discurso. Aqui podemos estabelecer um paralelo com o inédito do mundo do trabalho. Por que o trabalho é inédito? Porque o sujeito é um trabalhador que, ao mesmo tempo em que é social, é também particular. Ao mesmo tempo em que se trabalha sozinho, mesmo que nunca se trabalhe sozinho, o "eu" é um sujeito que traz muitos "eus" dentro dele, por isso nós falamos pela boca de muitos "eus", em uma rede de discursos. O social é o que constitui o "eu”, pois não está tudo dentro do sujeito, pronto, como já foi proposto por alguns estudiosos. Para Bakhtin (1992, p. 319 apud FIORIN, 2006, p. 167), "não existe objeto que não seja cercado, envolto, embebido em discurso, todo discurso dialoga com outros discursos, toda palavra é cercada de outras palavras".

Finalmente, acreditamos que todo texto pode suportar decodificações ou desestruturações. Na essência, todo texto são muitos discursos, já que a verdadeira complexidade de sua natureza polissêmica impede leituras repetitivas idênticas, ainda que no mesmo contexto cultural. Por isso, queremos destacar que o estudo do discurso é muito importante para compreender e interpretar as análises sobre o trabalho e para compreender a criação dos efeitos de sentido, que só podem ocorrer dentro de uma contextualização, pois a relação de trabalho nunca é uma situação isolada. Assim, a linguagem é um produto do trabalho e também atividade constitutiva do ser humano, revelando a centralidade do trabalho e a hegemonia dos discursos.

\subsection{A atividade de comunicação e trabalho e as hipermediações}

Neste contexto de tantas mudanças, amparados por Folcher e Rabardel (2007), cabe questionar se, com o buscador do Google e os tablets, por exemplo, estaríamos mudando a nossa cultura? Acreditamos que os meios de comunicação acompanham o seu tempo histórico: há quem afirme, por exemplo, que a Primavera Árabe ocorreu por conta do Twitter. Certamente, esse não foi o único elemento motivador do levante, mas contribuiu de forma 
interessante para a sua repercussão, como não seria possível algumas décadas atrás. Williams (2011), como se prevendo o futuro, afirma que

nas sociedades do século XX [...] os meios de comunicação como meios sociais de produção - e, em relação a isso, a produção dos próprios meios de comunicação - assumiram uma importância nova dentro da característica comunicativa em geral ampliada das e entre as sociedades modernas. [...] Além disso, esse desenvolvimento eminente ainda está em uma fase relativamente inicial e, sobretudo na indústria de eletrônicos, certamente irá muito além. (WILLIAMS, 2011, p. 73).

Manuel Castells (2009), que trata das transformações tecnológicas e o impacto nas relações interpessoais por conta dessas mudanças, questiona se estaríamos vivendo uma revolução nas comunicações. Ele mesmo responde, ao afirmar que,

en primer lugar, existe una transformación tecnológica basada en la digitalización de la comunicación, la interconexión de ordenadores, el software avanzado, la mayor capacidad de transmisión por banda ancha y la omnipresente comunicación local-global por redes inalámbricas, de manera creciente con acceso a Internet. (CASTELLS, 2009, p. 89).

No entanto, ainda restam muitas dúvidas. O que a internet traz de novo para esse sujeito que produz conteúdo na rede? O usuário se relaciona além de suas fronteiras ou fala apenas com a sua comunidade? Como encontrar a produção desejada em meio a tanto volume? É evidente que a internet coloca uma problemática e uma linguagem novas, mas suas múltiplas possibilidades de interação, no fim, apenas devolvem ao sujeito sua condição de sujeito, capaz de produção, diferente da visão hegemônica proposta pelas teorias tradicionais da comunicação, em que ele sempre era um receptor raso, que no máximo reproduziria o conteúdo. Ao menos sabemos que a internet não nos garante sermos vistos ou ouvidos, mas nos coloca em uma rede onde potencialmente podemos ser encontrados. Vivemos hoje a

passagem de uma sociedade dos meios, responsáveis pela veiculação de mensagens para as massas, para uma sociedade midiatizada, em que os meios não apenas constroem e fazem circular sentidos, mas configuram uma ambiência e redefinem nossa experiência. Tais reflexões não alcançam, entretanto, pensar a sociedade em rede no marco do qual essa ambiência organizada pela mediação das mídias se torna responsável por uma interconexão em escala antes inconcebível e a partir de uma participação individual e coletiva, implicando em reordenamentos nos processos 
comunicacionais, incluindo aqueles no âmbito da recepção e que envolvem especialmente as materialidades da internet e seus possíveis usos pela sociedade. (COGO; BRIGNOL, 2011, p. 79).

A hipermediação então, conceito central do livro de Scolari (2008), é entendida do ponto de vista do uso da internet, pois dentro desse espaço virtual, o usuário é impacto por diversos tipos de leitura e de produção, sendo que a comunicação pode se dar de um para um ou de um para muitos. Como já afirmamos, a maneira de se relacionar com a tecnologia depende dos usos, do momento histórico. E assim, um pouco na contramão da tendência atual, Scolari (2008) acredita que a tecnologia não é tudo, opinião com a qual concordamos. Isso porque ele tem uma postura mais reflexiva diante do tema, e entende de maneira dialética as transformações da cultura a partir das inovações tecnológicas, trazendo novas maneiras de pensar o universo "ponto com", do ponto de vista da produção e do consumo. Conforme Cogo e Brignol (2011),

\begin{abstract}
um primeiro aspecto que se torna necessário destacar em torno das transformações provocadas por essa outra ambiência das redes sociais é o de que um meio não substitui o outro, assim como os modelos de comunicação não são imediatamente suplantados por novas experiências midiáticas. O que percebemos é a complementaridade entre diferentes meios de comunicação, a proliferação da oferta midiática e a ampliação dos usos possíveis oferecidos para cada um deles ou, cada vez de forma mais incisiva, entre eles e de forma combinada. Assim, podemos dizer que o modelo de comunicação massiva se mantém e pode ser identificado em lógicas presentes na própria internet, mas é impactado por um modelo de comunicação que se baseia, entre outros aspectos, na relação entre as mídias, em um espaço de participação maior do público na produção da informação e de autonomia no processo comunicativo. (COGO; BRIGNOL, 2011, p. 83).
\end{abstract}

Este cenário influencia os laços de trabalho, que estão mudando a olhos vistos. Hoje, já não é mais um anseio dos jovens profissionais trabalhar a vida inteira em uma mesma empresa - e tal postura também não é mais bem vista pelo próprio mercado. Então, qual o significado do mundo do trabalho para uma juventude cada vez mais tecnológica, que em breve irá dominar a sociedade? Em uma tentativa de encontrar algumas respostas, iremos analisar o caso do Google, muito idealizado pela Geração Y como o ambiente de trabalho ideal.

\title{
2.4 O ambiente de trabalho do Google
}


De acordo com pesquisas em informações publicadas no site da própria empresa (YAMAOKA, 2005), os fundadores Larry Page e Sergey Brin se conheceram durante o doutorado na Universidade de Stanford, nos Estados Unidos, em 1995. No ano seguinte, criaram um mecanismo de pesquisa (inicialmente chamado de BackRub) que usava links para determinar a importância de páginas individuais. Esse mecanismo evoluiu e, já em 1998, nascia o Google, um trocadilho com a palavra "googol”, o termo matemático para um número 1 seguido de 100 zeros.

Sem dúvida, o buscador é o carro-chefe da empresa. Mas além dele, hoje o Google oferece gratuitamente cerca de 30 produtos para qualquer usuário que acesse seu conteúdo, além de soluções para empresas, sendo que sua grande fonte de renda é a publicidade. Em menos de 15 anos de existência, a organização lançou serviços que a mantém na vanguarda do mercado, como o Google AdWords em 2000, o Gmail em 2004, Google Maps em 2005, o Youtube em 2006, o Android em 2007, o Chrome em 2008 e, mais recentemente, o Google+ em 2011. Assim, em poucos exemplos, é possível compreender o impressionante desenvolvimento da organização, cuja missão é “organizar as informações do mundo e tornálas mundialmente acessíveis e úteis".

Ao se fazer uma busca no Google, aquela aparente infinidade de resultados promove a sensação, ao menos potencialmente, de conhecer o mundo. No entanto, os resultados aparecem conforme suas buscas anteriores, seus caminhos percorridos na web. Então, aquilo não é o mundo, e sim, um mundo criado especificamente para você. Nessa linha, MartínBarbero (2004) destaca

a necessidade de enfrentar o pensamento único que legitima a ideia de que a tecnologia é hoje o 'grande mediador' entre os povos e o mundo, quando o que a tecnologia medeia hoje mais intensa e aceleradamente é a transformação da sociedade em mercado, e deste em principal agenciador da mundialização (em seus múltiplos sentidos contrapostos). (MARTíNBARBERO, 2004, p. 229)

Assim, além de praticamente definir o jeito como usamos a rede hoje, o Google ajuda a difundir uma forma de trabalho alternativa, muito distante das tradicionais linhas de produção, ainda que essas novidades se deem sempre dentro de certos parâmetros. De qualquer maneira, seu jeito descontraído e cheio de benefícios para o empregado conquistou, já em 2007, o primeiro lugar na pesquisa Great Place to Work dos Estados Unidos, publicada pela revista Fortune. 
Em uma sondagem realizada pela autora com cinco profissionais que trabalham no escritório do Google na cidade de São Paulo, foi possível captar um pouco das percepções desses trabalhadores sobre o ambiente de trabalho da empresa, isso porque, "nesse percurso de descobertas, as perguntas permitem explorar um assunto ou aprofundá-lo, descrever processos e fluxos, compreender o passado, analisar, discutir e fazer prospectivas" (DUARTE, 2005, p. 63). A seleção dos informantes foi feita por conveniência, tendo como principal critério a proximidade dos profissionais entrevistados com a pesquisadora. As entrevistas em profundidade (semi-aberta) foram realizadas entre 13 de novembro e 04 de dezembro de 2012, amparadas por um roteiro de questões-guia. Todas as conversas foram gravadas e posteriormente transcritas para a análise das informações (DUARTE, 2005).

Por questões de confidencialidade, não iremos revelar os nomes ou cargos dos profissionais entrevistados para este artigo, que têm um perfil semelhante: todos pertencem à Geração Y, estudaram em universidades de primeira linha, tiveram experiência no exterior, têm inglês fluente e não pensam em sair do Google neste momento. Vale destacar que, apesar de todos serem graduados em comunicação, trabalham em diferentes setores da empresa, em um exemplo prático da diluição das fronteiras dos profissionais do campo.

- Profissional A, homem, 29 anos, graduado em publicidade e propaganda e mestrando em comunicação, trabalha no Google há três anos.

- Profissional B, mulher, 26 anos, graduada em propaganda e marketing e pósgraduada em administração, trabalha no Google há dois anos e sete meses.

- Profissional C, homem, 27 anos, graduado em publicidade e propaganda, trabalha no Google há um ano e nove meses.

- Profissional D, homem, 28 anos, graduado em publicidade e propaganda, trabalha no Google há três anos e quatro meses.

- Profissional E, mulher, 27 anos, graduada em relações públicas e pós-graduada em marketing, trabalha no Google há um ano e meio.

É fato que, para manter em funcionamento uma organização com um ritmo tão frenético, é necessária uma mão de obra expressiva. Hoje a empresa possui cerca de 30.000 "googlers" (termo utilizado pela organização para denominar seus trabalhadores) em cerca de 70 escritórios, em mais de 40 países ao redor do mundo. Embora os escritórios sejam diferentes entre si, sempre serão encontradas algumas características em comum: murais e decorações que expressam a personalidade local, videogames, mesas de sinuca, pianos, cafés e pequenas cozinhas abastecidas com alimentos saudáveis e quadros brancos para as ideias inesperadas. Seus escritórios são projetados para incentivar as interações entre os funcionários 
dentro e entre as equipes, e para estimular brincadeiras e conversas sobre o trabalho, inclusive nas reuniões gerais, que acontecem semanalmente. Como afirma Casaqui e Riegel (2008), pode-se observar um

fenômeno comunicacional da publicização do ambiente de trabalho do Google, que alimenta o "sonho de consumo" de milhares de jovens pelo mundo, sintonizados com a cibercultura e com bens culturais partilhados globalmente: o de trabalhar nessa empresa. São imagens de um ambiente de produção, representações sociais de atividade criativa espetacularizada, que mobilizam o imaginário contemporâneo do trabalho ideal. [...] O sentido da criatividade no Google, como algo ligado à manifestação do jogo no trabalho, vem servir à estratégia mercadológica que "transborda" do âmbito interno da instituição ao exterior, dos "desenvolvedores" (termo que designa os funcionários da instituição, segundo a própria empresa) aos consumidores internautas, em especial, mas para qualquer um que tenha acesso às imagens do ambiente de trabalho da corporação: há o revestimento de elementos lúdicos, como óculos sociais que ressemantizam os intrincados e automatizados processos que regem as tecnologias do serviço de busca Google. (CASAQUI; RIEGEL, 2008, p. 166-167; 171).

Não há como ficar indiferente ao visitar um escritório do Google. O ambiente é muito diferente dos escritórios tradicionais, a começar pelo fato de cada funcionário receber uma verba para decorar a sua estação de trabalho do jeito que desejar. Há pessoas que descansam em redes durante o expediente ou trabalham de bermuda e chinelos, o que reforça o ambiente quase mítico - reforçado pela imprensa - construído no imaginário dos trabalhadores que almejam entrar para a organização. E, rompendo com uma das grandes convenções do mundo do trabalho, não há cobrança por horários ou horas trabalhadas, mas sim por resultados alcançados. No entanto, todos os entrevistados costumam trabalhar as habituais oito horas diárias. Nas palavras do profissional A: "você sabe o que você tem que fazer, e você faz no tempo em que você tem que fazer. Ninguém vai olhar torto para você se você for jogar videogame no meio da tarde, se for fazer uma massagem, se for tirar um cochilo... ninguém fica com essa cobrança de 'ah, você não está trabalhando'. Você não tem que mostrar que está trabalhando [...] entrega o que você tem que fazer e ponto final. Rola uma confiança nesse sentido que eu acho bem legal". Mas ele reconhece que há "uma boa dose de marketing, com certeza $[. .$.$] não é que a galera fica o dia inteiro jogando videogame ou o dia inteiro na rede.$ Não. A galera trabalha duro, é um trabalho pesado. [...] A gente usa sim, não é fachada, mas a impressão que as pessoas têm de fora é que é mais mamata do que realmente é. É trabalho 
mesmo, não é brincadeira não [...] É trabalho: você tem que acordar cedo, você tem chefe, você sempre quer ganhar mais... é tudo igual.".

Pelas entrevistas, pudemos averiguar que o ambiente dos escritórios é sim considerado um diferencial pelos trabalhadores, mas eles têm consciência da estratégia de comunicação criada em torno disso. Todos relatam que, no primeiro mês de trabalho, tantas novidades geram um encanto, mas depois, isso é incorporado ao dia-a-dia das atividades. O entrevistado A, por exemplo, diz que costuma almoçar mais rápido (no refeitório do escritório), para poder jogar videogame e sinuca com um grupo de colegas, ou seja, realiza essas atividades dentro da clássica "uma hora de almoço". A entrevistada $B$, entretanto, diz que não costuma utilizar das atividades de lazer oferecidas pela empresa, mas que para ela é uma grande benesse poder alterar o seu ambiente de trabalho entre a sua mesa, a rede ou a varanda, por exemplo, para atividades que exigem inspiração ou maior concentração. Aqui vale ressaltar que, apesar da mobilidade existente, pelo fato de todos os trabalhadores do escritório possuírem notebooks, a área de recursos humanos orienta que os profissionais trabalhem o maior tempo possível em suas mesas, por questões de ergonomia, mas não se trata de uma política oficial e não haverá repreensão de o trabalhador fizer diferente. O entrevistado C diz que costuma fazer massagens e tirar cochilos no meio da tarde para relaxar e ampliar sua capacidade de concentração. $\mathrm{O}$ entrevistado D contou que costuma tomar café da manhã e ler o jornal na empresa, antes de começar o trabalho, muitas vezes ainda de pijama e a entrevistada E afirmou preferir os happy hours promovidos pela empresa às quintas-feiras (Thanks God Its Almost Friday), que contam inclusive com bebida alcoólica. E todos são unânimes em um ponto: esses benefícios são utilizados pela maioria dos trabalhadores sem exageros, e que não há repreensão por parte dos gestores. Quando é notado algum excesso, o gestor dará um feedback para que o funcionário utilize melhor o seu tempo, mas jamais falará que ele pare de jogar videogame, por exemplo.

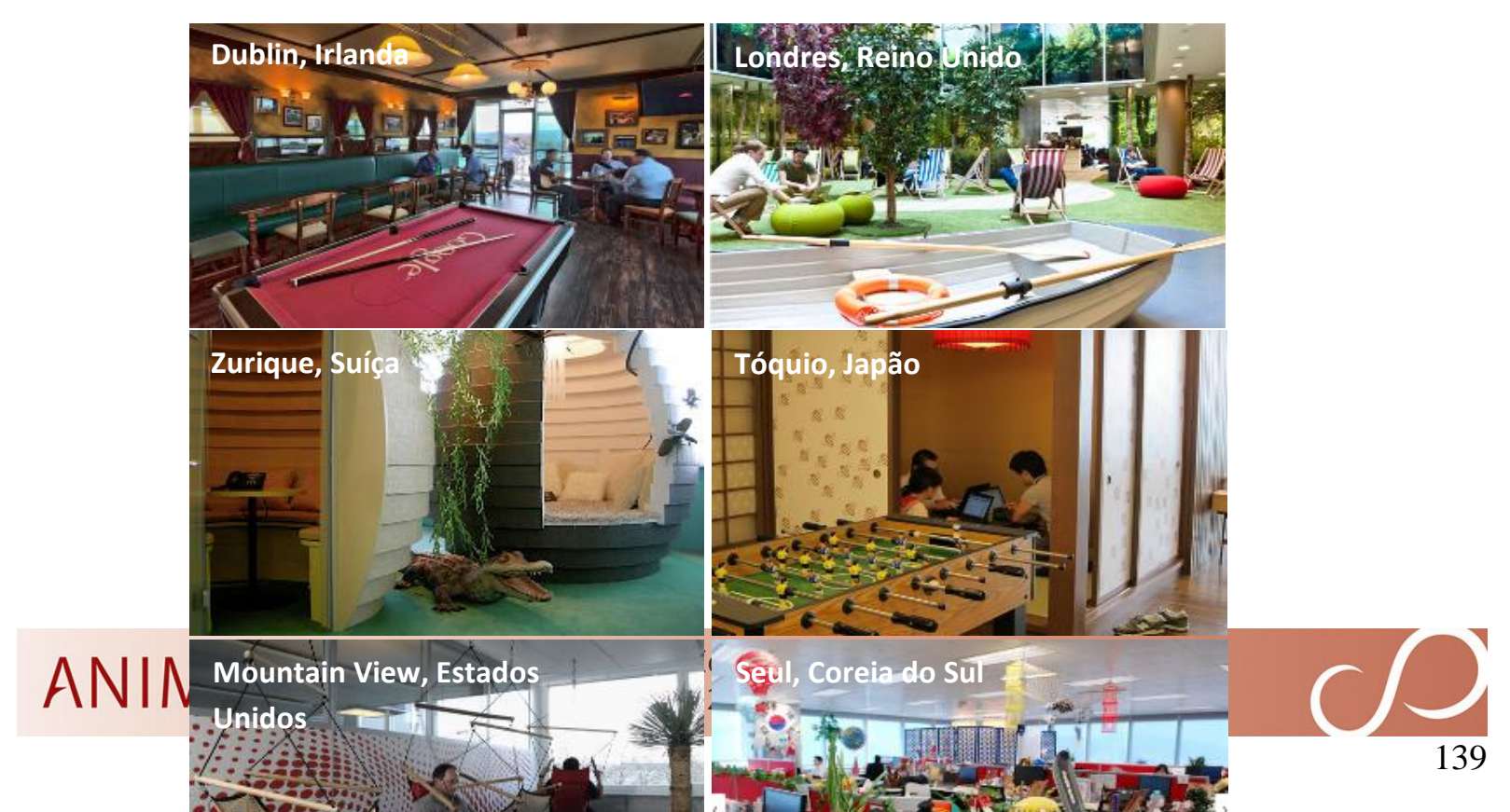


Figura 1 - Escritórios do Google. Fonte: http://www.google.com.br/about/company/facts/culture/

No entanto, há um propósito muito sério por entre as salas de reunião com nomes como Bambolê, Atari e Playmobil, bandeiras de times de futebol e bichinhos coloridos nas mesas. A empresa pode, sim, deixar que o funcionário defina seus horários - contanto que ele seja rigoroso no cumprimento das tarefas - e compartilhar informação - contanto que ele zele seriamente pelo sigilo, tanto quanto qualquer alto executivo. Esse relacionamento revela o que os funcionários mais apreciam na companhia, para além dos benefícios e da descontração: a autonomia individual, a circulação livre da informação e a liberdade de comunicação e debate, independentemente de hierarquia. Inclusive, essa transparência, para a entrevistada B, é um dos grandes diferenciais da companhia: “o Google é muito transparente com os funcionários. Todos os números, todas as decisões, todos os erros, todos os acertos são compartilhados com todo mundo. E eu acho que para ter essa transparência, e para ter a confiança que a pessoa pode dormir, pode fazer o que quiser, pode ouvir e confiar que ela vai guardar [...] para isso tem que investir muito em processo seletivo”. Esses são alguns dos pontos centrais de uma cultura definida pelos fundadores da companhia, sintetizada em dez verdades, uma espécie de filosofia corporativa pregada pela empresa. Já no primeiro dia no Google, o novo funcionário recebe uma série de orientações sobre a forma como a empresa espera que ele trabalhe e quais são as prioridades. No entanto, constatamos nas entrevistas que esses direcionamentos não estão tão claros para os trabalhadores, com exceção do primeiro, sempre muito presente no dia-a-dia de todos.

1. Concentre-se no usuário e tudo mais virá.

2. É melhor fazer algo realmente bem.

3. Rápido é melhor que devagar.

4. A democracia funciona na web.

5. Você não precisa estar em sua escrivaninha para precisar de uma resposta.

6. É possível fazer dinheiro sem fazer o mal.

7. Sempre haverá mais informações.

8. A busca por informações cruza todas as fronteiras.

9. É possível ser sério sem usar terno. 
10. Excelente ainda não é o bastante.

Por meio da nossa sondagem, podemos inferir que um dos grandes diferenciais da empresa é o recrutamento e seleção de seus trabalhadores. Ter acesso a esse ambiente de trabalho, entretanto, não é das tarefas mais fáceis. As vagas do Google estão entre as mais concorridas das empresas privadas do país. Para cada oportunidade anunciada em seu site, o departamento de recursos humanos recebe, em média, mais de 200, currículos do Brasil e de outros países. Apesar da aura de "emprego perfeito", de acordo com Silveira (2012), o "mundo real mostra que os funcionários das melhores empresas trabalham tanto ou até mais do que os demais. São tão ou mais cobrados por resultados e precisam provar a cada dia estar capacitados para desempenhar o seu papel". Para a contratação dos trabalhadores, a empresa prega dar preferência à capacidade em detrimento da experiência, o que foi confirmado em nossa sondagem, uma vez que nenhum dos profissionais tinha experiência prévia no setor de tecnologia. Talvez por isso trabalhar no Google seja o sonho de muitos, em especial dos jovens da famosa Geração Y, que têm pressa de crescer no emprego, não vivem sem uma parafernália tecnológica e não pensam duas vezes antes de mudar de trabalho (LOIOLA, 2009). Para a profissional B, a motivação para querer trabalhar no Google foi "ter uma experiência no melhor dos cenários corporativos, para entender como as coisas funcionam em uma grande empresa, e eu tinha essa referência que o Google era a melhor grande empresa para se trabalhar. Então foi um pouco pelo tamanho e pela cultura [...] os valores muito alinhados. Sabe, eu não queria trabalhar em uma empresa que tivesse uma missão, uma visão com a qual eu não concordasse e eu gosto muito do porquê o Google existe [...] foi um pouco da identificação com os valores e a vontade de trabalhar em um lugar grande, para aprender bastante”. Parte dessa fala já revela a prévia adequação ao discurso da empresa. Mas, para ser contratado pelo Google, é necessário passar por um longo e rigoroso processo seletivo, onde são privilegiadas as indicações dos próprios trabalhadores, que ganham um bônus em dinheiro se sua recomendação for a escolhida. Dessa maneira, o Google apresenta uma grande assertividade em suas contratações e consegue atrair os talentos em um mercado em ascensão, ainda com grande carência de profissionais qualificados. E essa qualificação dos profissionais é reconhecida internamente; conforme o entrevistado D, “as pessoas são muito boas, são muito competentes [...] Isso pesa bastante [...] em outros trabalhos, eu pensava 'por que tenho que trabalhar com esse cara?' Aqui não.. É difícil você ver alguém despreparado aqui’. E o que chama a atenção é justamente a especificidade e contemporaneidade dessa mão de obra, que desenvolve funções até alguns anos atrás inexistentes - e, mais que isso, sequer imaginadas. 
Certamente sua cultura não conta com a admiração de $100 \%$ dos quadros da organização. Mas se não há o tão procurado emprego perfeito, o que faz a diferença? O que o Google oferece de diferente das demais empresas? A resposta está em um conjunto de fatores que dá aos "googlers" a certeza de trabalhar em um lugar especial. Indiscutivelmente, é uma empresa que valoriza como poucos os seus empregados, e por isso consegue atrair o tipo de profissional que precisa: jovem, criativo e colaborativo.

Para entender o segredo dessa atração "magnética" que o Google exerce sobre os profissionais, Fábio Coelho (ELIAS, 2011), presidente da subsidiária brasileira, afirmou que o diferencial da companhia é "uma conjunção perfeita de fatores. Isso começa com uma proposta de trabalho altamente diferenciada aliada a um produto bom e inovador. É uma plataforma de publicidade, comunicação e mídia que subverte o modelo como essas coisas eram feitas. Some-se a isso um enorme potencial de crescimento de nosso mercado, o digital, e o que temos é uma situação muito boa. A publicidade online movimentou US\$ 26 bilhões no ano passado. E isso não é ainda $10 \%$ de tudo o que a publicidade movimenta no Brasil. Ou seja, é um mercado que só tem a crescer”. Suas práticas chamam a atenção, mas podem, pelo menos em tese, ser aplicadas por qualquer empresa, seja qual for seu tamanho ou setor de atuação. Por isso, quando questionado sobre por que o Google é uma boa empresa para trabalhar, responde que "eu poderia citar a série de benefícios que ele oferece, mas isso é só o que é tangível. E o tangível é copiável. Qual é o valor do tíquete-refeição, há sala de massagem, a empresa subsidia a formação dos funcionários? Tudo isso é copiável. O maior valor do Google, para mim, é o intangível. É a oportunidade de fazer parte disso tudo, estar em um espaço com um monte de pessoas que sabem que o que fazem tem um impacto gigantesco na vida das pessoas".

Identificamos que o Google tem uma clara preocupação em reconhecer o bom desempenho dos funcionários que se destacam na realização do seu trabalho, com uma política agressiva de premiações em dinheiro, além de um pacote de benefícios diferenciado, que inclui licença paternidade ampliada, reembolso de mensalidade de internet banda larga e a possibilidade de levar o animal de estimação para o trabalho. Os entrevistados, inclusive, destacaram essa preocupação da empresa em tornar o dia a dia dos trabalhadores mais fácil, algo que agrega muito valor, sobretudo em grandes cidades, onde os escritórios do Google estão instalados. Mas os funcionários têm uma visão crítica dos benefícios proporcionados pela empresa. O entrevistado A, por exemplo, afirma que "isso é uma coisa muita clara [...] todo mundo sabe que isso faz parte do salário [...] e a galera tem noção que poderia ganhar bem mais se não tivesse aqueles benefícios. Então ninguém fala 'nossa, que lindo, o Google é 
maravilhoso!". No entanto, vale destacar que nenhum dos entrevistados se enxerga voltando a trabalhar em um escritório "normal". E não por conta apenas benefícios e dos "penduricalhos" como mesas de sinuca e redes, mas sim pelo ambiente amistoso, formado por profissionais de alta performance. Para a profissional B, "nem sempre sobra tempo para jogar videogame, mas só o fato dele estar lá, e de as pessoas não acharem ruim se você for lá jogar, cria um ambiente gostoso, um cultura diferente $[\ldots]$ cria um dia a dia mais divertido [...] você não vai ser julgado por chegar um pouco mais tarde com uma roupa de academia ou por estar andando descalço". Outro atributo reconhecido como de grande valor pelos entrevistados é o fato de haver uma grande interação com grupos de trabalho, inclusive com pessoas de outros países. As viagens para escritórios do Google no exterior também são frequentes. Quando da realização deste artigo, por exemplo, a entrevista pessoal com a profissional B teve que ser cancelada, por conta de uma viagem ao Japão, e acabou sendo feita por telefone.

Todos os entrevistados reconhecem que tiveram que aprender uma nova linguagem para trabalhar na empresa, por conta de uma espécie de "dialeto interno" utilizado pelos empregados, mas nenhum afirmou ter tido grande dificuldades em relação a isso. Talvez porque, para todos eles, esse ambiente de tecnologia é algo muito natural, e muito presente em suas vidas, antes mesmo de se tornarem um "googler”, reflexo da Geração Y. Um exemplo mencionado pelo profissional A é receber uma resposta de e-mail apenas com “+1”, que significa que a pessoa está de acordo, em uma linguagem derivada do Google+. Por isso, organização preza por uma comunicação interna clara e eficiente, em que os trabalhadores são mantidos informados por diversos canais de comunicação, sobretudo os virtuais: intranet, emails e newsletters eletrônicas. Além disso, toda semana acontece um encontro entre todos os funcionários, incluindo os principais executivos (e o próprio presidente), conhecido no escritório de São Paulo como All Hands, para que todos saibam os rumos que a empresa está seguindo e quais os passos que precisam ser dados para que os objetivos sejam alcançados. Essa situação ideal de fala, de fundo habermasiano (HABERMAS, 1999), é pregada, pois todos têm, a priori, o mesmo direito de fala, em uma empresa de ambiente extremamente informal, onde os gestores são muito próximos de suas equipes e mantêm um relacionamento sem barreiras que permite dar e receber feedbacks constantemente e evitar ou corrigir rapidamente possíveis falhas. No entanto, acreditamos que a situação ideal de fala é utópica, pois as pessoas ocupam lugares diferentes na organização, mas há que se destacar que até mesmo o estagiário tem a possibilidade de ser ouvido, porque a organização percebeu que, em tempos de Geração Y, deles podem surgir ideias interessantes para o negócio. 
Ainda assim, a estrutura é extremamente horizontalizada, com pouquíssimos níveis e grupos de trabalho muito reduzidos. Então, mesmo que o profissional seja responsável por um projeto grande, é pouco provável que ele tenha uma equipe. Pela sondagem, pudemos detectar que isso é tido como um ponto negativo, e que os cargos vão representar mais a função que o trabalhador desempenha que um nível hierárquico. Nessa linha, em entrevista à revista Época (CORONATO, 2011), Alexandre Hohagen, diretor-geral para a América Latina, afirmou que "aqui, é preciso desaprender e aprender a trabalhar de novo. Importa menos seu cargo e mais sua capacidade de colaborar, convencer, influenciar, organizar uma rede. A hierarquia tem seu valor, mas ele é menor".

Por fim, quando questionados por que acreditam que o Google se destaca em rankings de melhor empresa para se trabalhar, as respostas foram muito parecidas, pois todos os profissionais entrevistados acreditam que é uma consequência natural do privilégio da empresa de poder atrair as pessoas com o perfil desejado. Para o profissional A, "por causa desse esquema de tratar o funcionário, eles contratam muita gente boa, que cria coisas boas para eles [Google]. Então, eles não estão fazendo um favor para ninguém [...]. A proposta deles é a seguinte: eu quero atrair as pessoas mais legais, mais interessantes, que vão fazer coisas mais legais para a empresa. Então é natural que eles ofereçam isso [os benefícios diferenciados]. [...] Tem demissão lá dentro, as pessoas rodam, porque o custo de manutenção de uma pessoa lá dentro é muito alto [...] Ninguém está fazendo caridade, eles não estão fazendo isso porque eles são bonzinhos. Eles apostam que o profissional que entrar lá vai entregar no nível que eles estão retribuindo, seja em salário, seja em benefício [...] Eles esperam um rendimento alto, então eles têm que retribuir da mesma forma". Se partirmos do pressuposto que todas as empresas esperam um alto rendimento, talvez o valor da forma de trabalho proposta pelo Google seja justamente o de reconhecer o seu trabalhador e se valer estrategicamente da comunicação para tornar público o que é de interesse da empresa.

\section{CONSIDERAÇÕES}

Com a reflexão realizada neste artigo, acreditamos que fica clara a impossibilidade de negar a centralidade do trabalho. Em um mundo onde se alardeia que "tudo é informação", é necessário aprender a enxergar a realidade e pensar a sociedade contemporânea e a comunicação sob uma nova ótica, a do mundo do trabalho.

Pela sondagem realizada, podemos afirmar que há uma grande estratégia de comunicação envolvendo os escritórios do Google, mas que o grande diferencial, de fato, é a 
qualidade dos profissionais atraídos pela empresa, em parte, justamente, por essas estratégias de comunicação. E, claro, para manter profissionais de alto desempenho, é necessário oferecer uma gama de benefícios interessantes. No entanto, mesmo em uma análise breve, fica claro que qualquer empresa poderia comprar uma mesa de sinuca e oferecê-la como recreação para seus funcionários. Mas, na prática, isso é uma coisa muito pequena, pois a própria lógica de produção da sociedade capitalista faz com que os trabalhadores não aproveitem tudo o que têm à sua disposição. Contudo, as próprias reportagens publicadas na imprensa alimentam essa fantasia, uma aura "mágica" em torno do assunto, como se fosse impossível manter os funcionários focados no trabalho com uma mesa de sinuca à disposição. Mas todos os que estão lá sabem que só têm esse tipo de benefício porque trabalham e entregam os resultados esperados. Ou seja, o grande "segredo" do Google para ter um ambiente de trabalho tão atrativo são coisas simples, que qualquer empresa pode ter, suportado pela alta qualidade dos processos de persuasão. A diferença é a forma como a empresa trabalha com isso, o modo como ela transmite ao funcionário o senso de responsabilidade de poder usufruir tudo o que está à disposição dele, mas sem deixar de entregar os resultados esperados pela empresa. Além disso, essa análise, ainda que breve, reforça a discussão da centralidade do trabalho, mostrando que na empresa os processos de comunicação foram incorporados como método de trabalho.

Acreditamos, por fim, que o Google se destaca por seu ambiente de trabalho porque é a empresa que melhor capturou o dinamismo das novas gerações, o modo como essas pessoas gostam de se relacionar, se comunicar e trabalhar, e com que agilidade. E o grande mérito é fazer isso por meio de artifícios simples. No entanto, outras empresas parecem não saber como lidar com esse cenário. Por isso é tão importante sua seleção criteriosa, a fim de garantir que foram escolhidas as pessoas certas para trabalhar nesse novo tipo de ambiente, que pode se tornar cada vez mais comum no mundo do trabalho.

\section{REFERÊNCIAS}

BAKHTIN, Mikhail. (Volochinov). Marxismo e filosofia da linguagem: problemas fundamentais do método sociológico na ciência da linguagem. São Paulo: Hucitec, 2002.

BRAVERMAN, Harry. Trabalho e capital monopolista: a degradação do trabalho no século XX. 3. ed. Rio de Janeiro: Zahar, 1981.

CASAQUI, Vander; RIEGEL, Viviane. Google e o consumo simbólico do trabalho criativo. Revista Comunicação, Mídia e Consumo. São Paulo, v. 6, n. 17, p. 161-180, nov. 2008. 
CASTELLS, Manuel. Comunicación y poder. Madrid: Alianza, 2009.

COGO, Denise; BRIGNOL, Liliane Dutra. Redes sociais e os estudos de recepção na internet. MATRIZes - Revista do Programa de Pós-Graduação em Ciências da Comunicação da Universidade de São Paulo. São Paulo, a.4, n. 2, p. 75-92, jan./jun. 2011.

CORONATO, Marcos. O jeito Google. Época, São Paulo, 11 jan. 2011. Disponível em: <http://revistaepoca.globo.com/Revista/Epoca/1,EMI164680-16165,00.html>. Acesso em 02 dez. 2012.

DUARTE, Jorge. Entrevista em profundidade. In: DUARTE, Jorge; BARROS, Antonio. Métodos e técnicas de pesquisa em comunicação. São Paulo: Atlas, 2005. p.62-83.

ELIAS, Juliana. Fábio Coelho: como passar no vestibular do Google. Época, São Paulo, 24 ago. 2011. Disponível em: < http://revistaepoca.globo.com/Negocios ecarreira/GPTW/noticia/ 2011/08/fabio-coelho-como-passar-no-vestibular-do-google.html>. Acesso em: 02 dez. 2012.

FIGARO, Roseli (Org.). Comunicação e análise do discurso. São Paulo: Contexto, 2012. Comunicação e trabalho para mudanças na perspectiva sócio-técnica. Revista USP. São Paulo, n. 86, p. 96-107, jun./ago. 2010.

Comunicação e trabalho: binômio teórico produtivo para as pesquisas de recepção. Mediaciones Sociales - Revista de Ciencias Sociales y de la Comunicación. Madri, n. 4, p. 23-49, 1. semestre 2009. Disponível em: <http://www.ucm.es/info/mediars/MediacioneS4/ Indice/FigaroR/figaroroseli.html>. Acesso em 15 nov. 2012.

FIORIN, José Luiz. Interdiscursividade e intertextualidade. In: BRAIT, Beth (Org.). Bakhtin: outros conceitos-chave. São Paulo: Contexto, 2006. p. 161-193.

FOLCHER, Viviane; RABARDEL, Pierre. Homens, artefatos, atividades: perspectiva instrumental. In: FALZON, Pierre. Ergonomia. São Paulo: Blucher, 2007. p.207-222.

GOOGLE. Sobre o Google. Disponível em: 〈http://www.google.com.br/about/company/〉. Acesso em: 25 nov. 2012.

HABERMAS, Jürgen. Teoría de la acción comunicativa. Vol. I. Madri: Taurus, 1999.

LOIOLA, Rita. Geração Y. Galileu, São Paulo, ed. 219, out. 2009. Disponível em: <http:// revistagalileu.globo.com/Revista/Galileu/0,EEDG7165-7943-219,00GERACAO+Y.html> Acesso em 08 dez. 2012.

MARTÍN-BARBERO, Jesús. Oficio de cartógrafo: travessias latino-americanas da comunicação na cultura. São Paulo: Loyola, 2004.

MARX, Karl; ENGELS, Friedrich. A ideologia alemã. São Paulo: Boitempo, 2007. 
NOUROUDINE, Abdallah. A linguagem: dispositivo revelador da complexidade do trabalho. In: SOUZA E SILVA, Maria Cecília; FAÏTA, Daniel (Orgs.). Linguagem e trabalho: construção de objetos de análise no Brasil e na França. São Paulo: Cortez, 2002. p. 17-30.

RADFAHRER, Luli. Homo dissatisfactens. MSG - Revista de Comunicação e Cultura. São Paulo, a. 2, n. 8, p. 28-29, jul. 2012.

SCHAFF, Adam. Linguagem e conhecimento. Coimbra: Almedina, 1976.

SCOLARI, Carlos. Hipermediaciones: elementos para una teoría de la comunicación digital interactiva. Barcelona: Gedisa, 2008.

SILVEIRA, Mauro. Os segredos do Google. Época, São Paulo, 19 set. 2012. Disponível em: $<$ http://revistaepoca.globo.com/Negocios-e-carreira/GPTW/noticia/2012/08/os-segredos-dogoogle.html>. Acesso em 02 dez. 2012.

VIGOTSKI, L. S. Pensamento e linguagem. 3. ed. São Paulo: Martins Fontes, 2005.

WILLIAMS, Raymond. Cultura e materialismo. São Paulo: Edunesp, 2011.

YAMAOKA, Eloi Juniti. O uso da internet. In: DUARTE, Jorge; BARROS, Antonio. Métodos e técnicas de pesquisa em comunicação. São Paulo: Atlas, 2005. p.146-163.

Original recebido em: 29/10/2012

Aceito para publicação em: Novembro de 2013

Tânia Oliveira Pereira

Mestranda do Programa de Pós-Graduação em Ciências da Comunicação na Universidade de São Paulo. Pós-graduada em Gestão Estratégica em Comunicação Organizacional e Relações Públicas (2011) e graduada em Comunicação Social - Relações Públicas (2007), ambas pela Escola de Comunicações e Artes da Universidade de São Paulo.

Maria Aparecida Ferrari

Possui graduação em Ciências Sociais pela Universidade de São Paulo (1976), graduação em Relações Públicas pela Faculdade Anhembi Morumbi (1981), mestrado em Ciências da Comunicação pela Universidade de São Paulo (1993) e doutorado em Ciências da Comunicação pela Universidade de São Paulo (2000). É professora da Escola de Comunicações e Artes da Universidade de São Paulo. 